\title{
RECENT ADVANCES IN HIGH-TEMPERATURE SUPERCONDUCTOR WIRE FABRICATION AND APPLICATIONS DEVELOPMENT*
}

\author{
by \\ John R. Hull and Kienneth L. Uherka \\ Materials and Componer.ts Technology Division \\ Argonne Nationai Laboratory \\ 9700 South Cass Avenue \\ Argonne, Illinois 60439
}

\begin{abstract}
The submrted manuseript has been authored by a contractor of the U.S. Govemment under contract No. W.31-109-ENG.3B. Accordingly, the U.S. Government relains a nonexctusive, royalty-tres license to publish or reproduce the publistied form of this contribution, of allow others to do so, for U.S. Government purposes.
\end{abstract}

To be submitted to 1992 Intersociety Energy Conversion Engineering Conference, San Diego, CA, Aug. 3-7. 1992.

*Work at Argonne National Laboratory was supported by the U.S. Department of Energy, Conservation and Renewable Energy, as part of a program to develop electric power technologv, under Contract W-31-109-Eng-38.

\section{DISCLAIMER}

This report was prepared as an account of work sponsored by an agency of the United States Government. Neither the United States Government nor any agency thereof, nor any of their employees, makes any warranty, express or implied, or assumes any legal liability or responsibility for the accuracy, completeness, or usefulness of any information, apparatus, product, or process disclosed, or represents that its use would not infringe privately owned rights. Reference herein to any specific commercial product, process, or service by trade name, trademark, manufacturer, or otherwise does not necessarily constitute or imply its endorsement, recommendation, or favoring by the United States Government or any agency thereof. The views and opinions of authors expressed herein dn not necessarily state or reflect those of the United States Government or any agency thereof.

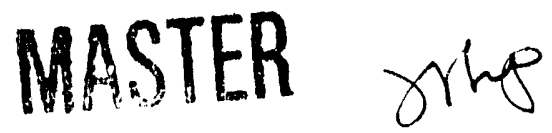

DISTRIBUTION OF THIS DOCUMENT is UNALINAITE 
Recent Advances in High-Temperature Superconductor Wire Fabrication and Applications Development

John R. Hull and Kenneth L. Uherka

Materials and Components Technology Division

Argonne National Laboratory

Argonne, IL. 60439

\section{Abstract}

In this paper, recent advances in fabrication of HTS wires are summarized, and detailed discussion is provided for developments in near- and intermediate-term applications. Near-term applications, using presently obtainable current densities, include: liquid-nitrogen depth sensors, cryostat current leads, and magnetic bearings. Intermediate-term applications, using current densities expected to be available in the near future include fault-current limiters and short transmission lines.

\section{INTRODUCTION}

Since the discovery of high-temperature superconductors (HTSs), our laboratory has been active in a broad spectrum of activities in fabricating the superconductors into useful wires and developing applications for these materials. Work at every stage of development has invariably involved industrial collaborations in order to accelerate commercialization. It has generally been accepted that most of the applications for HTSs will occur when they can be cooled with liquid nitrogen. These longer term applications include superconducting motors, magnetic energy storage, etc.. So far, there are no commercial HTS wires that have all the necessary properties to enable these applications. However, progress is rapidly occuring toward this end, and applications utilizing low and intermediate current densities and intermediate temperatures are being developed. This paper summarizes some of the progress made in wire development, discusses 
some of the remaining technical problems for wire fabrication, and discusses some of the near and intermediate term applications.

\section{HIGH-TEMPERATURE SUPERCONDUCTOR FAMILIES}

All of the HTSs now under investigation for practical magnet applications are copper oxide ceramics. Holczer et al. [1] and Rosseinsky et al. [2] first showed that the fullerene compound $C_{60}$, when properly doped, can exhibit high $T_{C}$ values. While there is considerable enthusiasm for their potential in applications as newer dopings with higher $T_{c} s$ are cliscovered, these superconducting organics are too new for this potential to be quantified, and these compounds are not discussed further in this paper.

There are three major families of ceramic HTSs. While the nomenclature is not totally consistent from researcher to researcher, a common abbreviation scheme denotes the families as YBCO, BSCCO, and TBCCO. For all HTSs, the oxygen content may vary somewhat, and this variation usually plays a minor role in determining some of the details of the physical properties. In addition, other elements are often substituted for the basic constituents in each family, occasionally resulting in significant improvements in one of the superconducting properties.

Wu et al. [3] discovered the first HTS, $\mathrm{YBa}_{2} \mathrm{Cu}_{3} \mathrm{O}_{7-x^{\prime}}$, where the subscript $\mathrm{x}$ denotes an amount less than unity. Others soon discovered that this YBCO compound could take the form $\mathrm{REBa}_{2} \mathrm{Cu}_{3} \mathrm{O}_{7-\mathrm{x}}$, where $\mathrm{RE}$ denotes "rare earth." The $\mathrm{T}_{C}$ of these compounds is approximately $92 \mathrm{~K}$, varying by several degrees with the specific. RE that is used. Most REs will form a superconducting compound in the YBCO family; however, $\mathrm{Pr}, \mathrm{Ce}$, and $\mathrm{Tb}$ do not. $\mathrm{REBa}_{2} \mathrm{Cu}_{3} \mathrm{O}_{7-\mathrm{x}}$ is often called the 123 compound after the subscripts for the first three elements. There is also a $124 \mathrm{YBCO}$ 
compound, with a $T_{c}$ of about $80 \mathrm{~K}$, that is more thermodynamically stable than the 123 phase. A 247 phase is also known.

The second family, discovered by Maeda et al. [4], has a basic constituent of Bi$\mathrm{Sr}-\mathrm{Ca}-\mathrm{Cu}-\mathrm{O}$ (hence BSCCO). Sometimes $\mathrm{Pb}$ is partially substituted for the $\mathrm{Bi}$, which seems to simplify the formation of pure phases. The two important phases of $\mathrm{BSCCO}$ are the 2212 compound, with a $\mathrm{T}_{\mathrm{C}}$ of about $80 \mathrm{~K}$, and the 2223 compound, with a $T_{c}$ of about $105 \mathrm{~K}$.

The third family, discovered by Zheng and Hermann [5], is Tl-Ba-Ca-Cu-O (TBCCO) and has many phases with high $\mathrm{T}_{\mathrm{c}} \mathrm{s}$; the highest, found by Parkin et al. [6], is $125 \mathrm{~K}$. Initially, the TBCCO family did not receive as much attention as the other two families, mainly because of the difficulty of isolating pure phases and in working with the volatile and somewhat toxic thallium. More recently, interest in the TBCCO family is increasing because of its potential for large current density at high temperatures and magnetic fields.

\section{WIRE FABRICATION}

Wire-making techniques such as plastic extrusion, oxidation of metallic precursors, and electrochemical deposition on a metallic substrate are capable of producing arbitrarily long lengths of HTS. However, typical state-of-the-art values of critical rurrent density $\left(\mathrm{J}_{\mathrm{C}}\right)$ values for long lengths of these wires are several thousand $\mathrm{A} / \mathrm{cm}^{2}$ in zero magnetic field and hundreds of $\mathrm{A} / \mathrm{cm}^{2}$ in magnetic fields greater than I T, e.g., as reported by Shi et al. [7]. Mankiewich et al. [8] demonstrated that high $J_{C}$ values at high field strengths could be obtained in thin films of HTS, proving that such performance is theoretically possible. However, despite continuing advances (e.g., by Busch et al. [9]), the production of long lengths of wire by thin-film processes is not yet known to be feasible. Several directional solidification techniques, e.g., by Salama et al. [10], have produced small samples of 
bulk HTS that approach the $\mathrm{J}_{\mathrm{C}}$ and magnetic field requirements of fusion magnets. However, it is not clear that these methods can be used to make long lengths of wire in a reasonable period of time.

One of the most promising developments in HTS wire-making has been in powder-in-tube fabrication with the BSCCO family, where Heine et al. [11] demonstrated $J_{C}$ values superior to that of low-temperature superconductor (LTS) wire in very high magnetic fields at $4 \mathrm{~K}$. Shibuta et al. [12] have measured critical current densities of $89 \mathrm{kA} / \mathrm{cm}^{2}$ at $4 \mathrm{~K}$ an a perpendicular magnetic field of $23 \mathrm{~T}$. Sato et al. [13] measured $\mathrm{J}_{\mathrm{c}} \mathrm{s}$ of more than $50 \mathrm{kA} / \mathrm{cm}^{2}$ in fields greater than $19 \mathrm{~T}$ in these materials at temperatures as high as $20 \mathrm{~K}$. The performance of these wires degrades substantially above 20 to $30 \mathrm{~K}$. So far, high $\mathrm{J}_{\mathrm{C}}$ values have been obtained only in short lengths of wire, but most researchers feel confident that long lengths of practical HTS wire with satisfactory performance at temperatures up to about 20 or $30 \mathrm{~K}$ can be developed with the powder-in-tube method.

\section{CRITICAL CURRENT DENSITY}

The major technical challenge for HTSs is to increase the $\mathrm{J}_{\mathrm{c}}$. Each of the HTS materials has its specific technical problems. For example, YBCO has difficulty passing current from one superconducting grain to the next. The BSCCO family does not have this problem, but instead seems to experience an intrinsic weakness in preventing the flow of magnetic flux through it at temperatures much above 30 K. Most of the TBCCO phases also seem to suffer from this flux-flow problem.

Ceramic materials consist of individual grains adhering to one another. In any superconductor, the grain boundaries of the material are in the normal state, and the superconducting current must quantum-mechanically tunnel through the boundary from one grain to the next. In $\mathrm{NbTi}$, this is not a problem, because the superconducting coherence length is several orders of magnitude greater than the 
grain boundary thickness, and the attenuation at each boundary is negligible. For HTSs, the coherence length is about $3 \mathrm{~nm}$, approximately the same as the grain boundary thickness. In the HTS, the result is a network of good superconducting grains connected by these barriers, know as "weak links." Any sort of contamination or improper processing produces thicker grain boundaries and even weaker links, and one of the goals in HTS materials development is to make exceptionally clean and thin grain boundaries.

One way to minimize the weak-link problem is to align the individual grains, and a number of processes have been investigated to achieve this end. Alignment is important because of the anisotropic nature of HTSs. With all of the copper oxide planes aligned, it is easier to pass current from one grain to the next. The BSSCO material is a micaceous compound and shears readily along certain planes, making it relatively easy to align when the material is rolled. This has been most readily achieved in a powder-in-tube process, in which the HTS powder is sealed in a silver tube and the tube then undergoes a series of reduction steps (drawing, swaging, or rolling) accompanied by heat treatment according to different schedules. In the YBCO compound, the only method that has yielded substantial alignment is various forms of melt-texturing, in which the material is solidified in a temperature gradient. Because of the limited rate at which the grains grow, this method is very slow and probably not appropriate for making long lengths of wire.

When a superconducting wire is operated in a magnet, magnetic flux will penetrate the superconductor. The combination of current through the wire and magnetic field perpendicular to the current produces a Lorentz force that tries to push the magnetic flux lines through the superconductor. For there to be no esistance in the superconductor, it is necessary that these flux lines be immobile, i.e., pinned in place. If the flux lines move, dissipation and heating occur, and highc. irrent-density magnets can experience severe heating, often leading to destruction. 
Flux pinning is one of the least understood aspects of HTSs. However, it is believed that thermal noise in the superconductor can de-pin flux lines, and the higher the operating temperature the more thermal noise is present. For lowtemperature superconductors (LTSs), flux flow was a minor irritation because the thermal noise was so low. At $77 \mathrm{~K}$, thermal noise is about 20 times higher than at 4 $\mathrm{K}$, and the problem is more severe. The different HTS materials appear to suffer from this problem to different extents. One theory [14] that is gaining acceptance attributes flux flow in HTSs to Josephson coupling between 2-dimensional pancake current vortices in adjacent superconducting layers. If the layers are close together then coupling is good and flux-flow is less of a problem. As the layer spacing increases, the coupling is worse. Because the phenomena causing the pinning is of the order of interlayer spacing, addition of flux pinning centers is unlikely to substantially affect the flux-flow behavior. Flux-flow is an intrinsic property of the HTS, and the best HTSs will be those with the closest interlayer spacing.

A summary of magnetic field versus temperature at which flux flow becomes a problem for different HTSs is shown in Fig. 1. Practically speaking, for a fixed temperature, it is unlikely that large current densities can be obtained for magnetic fields above that shown in the figure. As seen in Fig. 1, YBCO suffers almost no flux-flow problems until the critical temperature or critical magnetic field is reached. From a flux-flow standpoint, YBCO is an ideal material. If the weak-link problem could be solved in $Y B C O$, it would be the material of choice.

Of all the other HTS materials, only the 1223 phase of the TBCCO family appears to have the potential, from a flux-flow standpoint, to achieve useful magnetic field strengths at about $77 \mathrm{~K}$.Unfortunately, the TBCCO seems to react with $\mathrm{Ag}$, and the powder-in-tube methods that were successful with BSSCO will need to be modified for TBCCO. In addition, it is not yet known whether the 1223 phase of TBCCO will suffer from weak links, although, there is some suggestive evidence 
that it will not. DeLuca et al [15] reported achieving a transport critical current density of $10 \mathrm{kA} / \mathrm{cm}^{2}$ at $77 \mathrm{~K}$ when a $1 \mathrm{~T}$ magnetic field was applied perpendicular to a $3 \mu \mathrm{m}$ thick TBCCO film. Doping of this TBCCO may decrease the layer spacing and improve the current density further.

\section{MECHANICAL STRENGTH}

For a conductor to be useful in practice, it must withstand appreciable mechanical stress. Normal use may require thermal cycling, repeaied strain (during fabrication and operation), and consistent behavior over long lengths.

Ceramic materials are well known for their brittleness. Clearly, if a crack develops in an HTS wire, the current can no longer flow. Singh et al. [16] found that the addition of $\mathrm{Ag}$ to the HTS powder in the early stages of fabrication improves tensile strength and fracture toughness. Singh [17] produced sintered YBCO with flexural strength of more than $200 \mathrm{MPa}$ and with fracture toughness as high as 4.5 $\mathrm{MPam}^{1 / 2}$, which gives the HTS about the same toughness as a ceramic spark plug insulator. Even with these high numbers, one cannot bend the HTS into a magnet form after it is fired. Considerable improvements must be made before this is possible.

One solution to the brittleness problem is to wind the magnet in the green state and then react it in the heat treatment stage. This was done with $\mathrm{Nb}_{3} \mathrm{Sn}$, one of the two most commonly used low- $\mathrm{T}_{C}$ compounds, which is also brittle like a ceramic.

A second solution is to form the superconductor in the form of fine filaments. With a small enough diameter, the fibers can be bent to a considerably small radius after they are fired. So far, those processes that have produced fine filaments of HTS have not produced very high critical current densities. For example, Matsubara et al. [18] have produced 1-5 $\mu \mathrm{m}$ diameter whiskers of BSCCO that exhibit critical current densities of $73 \mathrm{kA} / \mathrm{cm}^{2}$ at $77 \mathrm{~K}$, but the current density falls off rapidly for 
magnetic fields less than $1 \mathrm{~T}$ when the field is applied parallel to the c-axis of the whisker.

\section{LIQUID-NITROGEN DEPTH SENSORS}

HTS liquid-nitrogen depth sensors are already commercially marketed by two companies. These sensors are typically long rods of HTS, usually YBCO, that are inserted vertically into a container of liquid nitrogen. To a first approximation, that part of the HTS immersed in the liquid is superconducting and that part above the liquid is in the normal state. A small current is passed through the sensor, and the voltage across the HTS is measured. To a first approximation, the voltage is linear with the length of HTS above the liquid nitrogen. Because only small currents are required, current densities can be low, and current densities in present extruded and sintered bulk HTSs are more than adequate. Good mechanical properties of the HTS and its support structure are the crucial features in this application.

\section{CURKENT LEADS}

The use of HTSs in cryostat current leads, delivering electrical power from ambient-temperature supplies to devices operating in liquid helium, is another near-term HTS application [19]. The advantage of HTSs in this application is that because joule heating is eliminated in the HTS part of the lead, heat leakage into the liquid helium is reduced, resulting in longer operating times for open systems and reduced refrigeration requirements for closed systems. Because the thermal conductivities of HTSs are relatively low, lead lengths can be relatively short. Current densities of $100-1000 \mathrm{~A} / \mathrm{cm}^{2}$ (at $\mathrm{T} \leq 77 \mathrm{~K}$ and $\mathrm{B} \leq 20 \mathrm{mT}$ ), obtainable with present bulk sintering methods, allow the use of leads that occupy a reasonably small volume and are not 
overly expensive in many designs. Lower current densities are also advantageous in providing a longer transient response time if part of the HTS becomes normal.

A vapor-cooled lead has superconducted $2 \mathrm{kA}$ in its HTS part and experimentally demonstrated that the helium boiloff from this lead was less than the theoretical best that could be expected from a normal-metal vaporcooled lead of the same current rating [19]. The helium boiloff from this lead as a function of current is shown in Fig. 2 and compared to theoretical calculations of ideal behavior in normal-metal leads optimized at various currents. Actual normal-metal leads typically have $10 \%$ or more higher boiloff than the theoretical values. Scale-up of this HTS lead design to larger currents associated with large-scale fusion magnets or superconducting magnetic energy storage should be relatively straightforward [20]. In this application also, good mechanical properties are important to ensure the integrity of the lead. For this reason, we have usually added silver (15 vol.\%) to the HTS powder before sintering to improve frac'ure toughness.

Hull [18] has shown that if the warmer end of the HTS part of the vaporcooled lead is thermally anchored to a heat exchanger at $77 \mathrm{~K}$, it is theoretically possible to reduce the helium boiloff to about 0.4 of the theoretical best for a copper lead, without danger of burnup. Further reduction of helium boiloff is possible, if absolute lead safety is sacrificed for safety over a finite time determined mainly by the current density. Experiments are underway to demonstrate lower values of helium boiloff, with the goal of obtaining 0.1 of the boiloff of an ideal normal-metal lead of the same current rating. 
Magnetic bearings constitute another near-term application for HTSs [22]. In this application, it is not necessary to transport current between grains of the HTS. Rather, current within each grain is sufficient to provide magnetization for the generation of magnetic pressure. Of course, if current does flow between grains, magnetization is improved; however, quite satisfactory performance may be generally obtained with only intergranular current flow. Considerable effort has been expended to elucidate much of the basic levitation phenomena associated with permanent magnets interacting with HTSs. As flux pinning has steadily improved and grain size in good quality specimens has increased, the magnetic pressures have also increased, so that magnetic pressures of $100 \mathrm{kPa}$ are now obtainable with a variety of processing methods based on melt processing of $\mathrm{Y}-\mathrm{Ba}-\mathrm{Cu}-\mathrm{O}$. This pressure is approximately equivalent to that obtainable with gas-film bearings, the most likely competitor at cryogenic temperatures.

A cylindrical permanent magnet levitated over an HTS forms a good bearing when the magnet rotates easily about its axis of symmetry but exhibits high stiffness to lateral and vertical displacements. It is sometimes stated that such magnets are frictionless, probably because there are no contacting parts. Strictly speaking, there will always be some rotational drag caused by eddy currents, magnetic hysteresis, or air friction, and, thus there will always be an effective coefficient of friction. Some HTS bearings reported in the literature have displayed relatively high coefficients of friction. An HTS bearing exhibited an equivalent coefficient of friction of $8 \times 10^{-6}$ [23]. We have since reduced this value to $4 \times 10^{-6}$ and have confidence that the coefficient can be reduced even further.

With a low coefficient of friction, HTS bearings have the potential for use in low-loss energy-storage flywheels. State-of-the-art conventional 
magnetic bearings typically have an effective coefficient of friction of about $10^{-4}$. Conventional roller bearings have even more friction. Even considering the refrigeration losses at $77 \mathrm{~K}$, low-loss HTS bearings should have lower loss and allow flywheels to spin longer than with any other bearing technology. We consider the low-loss HTS bearing an enabling technology for many flywheel applications and are pursuing several projects in this area.

\section{INTERMEDIATE-TERM APPLICATIONS}

Several additional applications should become viable if current densities at $77 \mathrm{~K}$ in long lengths of HTS can be increased slightly from their present values. A fault-current limiter (FCL) would take advantage of the rapid falloff in critical current density as the magnetic field increases. Under fault conditions, an increase in current would drive the HTS normal and significantly increase the impedance of the FCL, thus limiting the rise in current. For this application, extremely high current densities are not necessarily desirable. One must trade off the increased costs associated with low current density against the danger of overheating associated with high current density.

While long-distance utility transmission lines generally require very high current densities to be economical, there are a number of potential applications [24] for short-distance transmission lines that require current densities of only about $10 \mathrm{kA} / \mathrm{cm}^{2}$.

\section{INTERMEDIATE-TEMPERATURE APPLICATIONS}

As is now well known, Bi-Sr-Ca-Cu-O wire has demonstrated performance superior to that of low-temperature superconductor (LTS) wire 
in very high magnetic fields at $4 \mathrm{~K}$, and it appears likely that in the next several years, HTS wire will become available with good properties at temperatures up to 20 or $3 \mathrm{~J} \mathrm{~K}$. Operation at these temperatures will doubtless make many of the conventional superconductor applications more attractive due to lower refrigeration requirements compared to $4 \mathrm{~K}$. In addition, there are novel applications that become available, such as the system described below.

One concept study [ [5] has indicated that there rnay be some synergistic advantages in using liquid hydrogen (boiling point $20 \mathrm{~K}$ at $1 \mathrm{~atm}$ ) aboard a magnetically levitated (maglev) vehicle to power a turbine/generator that propels the train. The liquid hydrogen would also be used to cool the HTS levitation magnets.

The maglev concept discussed here uses electrodynamic suspension, in which repulsive levitation forces are prociuced between superconducting magnets aboard the vehicle and "image magnets" produced by eddy currents induced in a conducting guideway by the moving superconducting magnets. As is typical in this method, inherently stable levitation can be achieved with a relatively large guideway clearance, but conventional support means must be used at low speeds. The major advantage realized by the large clearance is larger tolerance values in the guideway, resulting in lower capital and maintenance costs.

In this concept, the vehicle levitation magnets are made from liquidhydrogen-cooled HTSs operating in persistent-current mode. The vehicle carries a large storage tank of liquid hydrogen but no refrigerator. The vehicle is propelled by a short-stator single-sided linear induction motor (LIM) or a short-stator homopolar synchronous motor (LHSM) that interacts with the guideway. Electrical power is provided to the motor from a generator driven 
by an air-breathing liquid-hydrogen turbine. The guideway is supported by a concrete structure and is divided into a levitation part, which consists of a continuous aluminum sheet, and a separate propulsion part, which consists of a continuous aluminum sheet backed by an iron strip. Small amounts of liquid hydrogren flow as needed from the storage tank to cool the levitation magnets and the windings of the motor and generator. The hydrogen then passes into the turbine and combusts with ambient air to provide the motive force for the turbine. Typically, the amount of hydrogen required for propulsion is larger than that required for cooling, and the bulk of the hydrogen flow to the turbine is provided by a direct line. The turbine exhaust consists mainly of water and oxygen-depleted air.

\section{CONCLUSIONS}

YBCO wires still suffer from weak links between the superconducting grains. This is overcome in melt-textured processe;, however, these methods have been slower than desired for commercial production. BSCCO wires are now being made in long lengths with extremely good current densities in high magnetic fields at temperatures as high as 20 to $30 \mathrm{~K}$. The 1223 phase of the TBCCO family is also snowing good promise as a superior material at even higher temperatures. The question of weak links in this material is presently being addressed.

A liquid nitrogen depth sensor is already commercially marketed by two companies. Cryostat current leads have been fabricated that have superconducted 2 $\mathrm{kA}$ and have demonstrated a helium boiloff that is less than the theoretical best obtainable from a pure metal lead. Work on producing even lower helium boiloff rates is in progress. Superconducting bearings have been fabricated that have exhibited an equivalent coefficient of friction of $4 \times 10^{-6}$. Such bearings have the potential for use in low-loss energy-storage flywheels. 
Intermediate-term applications, using current densities expected to be available in the near future, include fault-current limiters and short transmission lines. Other intermediate-term applications may make use of the excellent properties demonstrated by some of the HTSs at temperatures near $20 \mathrm{~K}$. Somewhat longer-term applications include superconducting motors and magnetic energy storage.

\section{ACKNOWLEDGMENTS}

This work was supported by the U. S. Department of Energy, Conservation ard Renewable Energy, as part of a program to develop electric power technology, under Contract W-31-109-Eng-38. We are indebted to our colleagues at ANL and sur numerous collaborators worldwide for contributing to the developments described in this paper.

\section{REFERENCES}

1. K. Holczer, O. Klein, S.-M. Huang, R. B. Kaner, K.-J. Fu, R. L. Whetten, and F. Diederich, Science 252 (1991) 1154.

2. M. J. Rosseinsky, A. P. Ramirez, S. H. Glarum, D. W. Murphy, R. C. Haddon, A. F. Hebard, T. T. M. Palstra, A. R. Kortan, S. M. Zaburak, and A. U. Makhija, Phys. Rev. Lett. 66 (1991) 2830.

3. M. K. Wu, J. R. Ashburn, C. J. Torng, P. H. Hor, R. L. Meng, L. Gao, Z. J. Huang, Y. Q. Wang, and C. W. Chu, Phys. Rev. Lett. 58 (1987) 908.

4. H. Maeda, Y. Tanaka, M. Fukutomi, and T. Asano, Japn. J. Appl. Phys. 27 (1988) L209.

5. Z. Z. Sheng and A. M. Hermann, Nature 332 (1988) 55.

6. S. S. P. Parkin, V. Y. Lee, E. M. Engler, A. I. Nazzal, T. C. Huang, G. Gorman, R. Savoy, and R. Beyers, Phys. Rev. Lett. 60 (1988) 2539. 
7. D. Shi, M. Xu, J. G. Chen, A. Umezawa, S. G. Lanan, D. Miller, and K. C. Goretta, Mater. Lett. 9 (1989) 1.

8. P. M. Mankiewich, J. H. Scofield, W. J. Skocpol, R. E. Howard, A. H. Dayern, and E. Good, Appl. Phys. Lett. 51 (1987) 1753.

9. H. Busch, A. Fink, and A. Muller, J. Appl. Phys. 70 (1991) 2449.

10. K. Salama, V. Selvamanickam, L. Gao, and K. Sun, Appl Phys. Lett. 54 (1989) 2352.

11. K. Heine, J. Tenbrink, and M. Thoner, Appl. Phys. Lett. 55 (19i, ) 2441.

12. N. Shibuto, M. Ueyama, H. Mukai, and K. Sato, Japn. J. ¿ippl. Phys. 30 (1991) L2083.

13. K. Sato, T. Hikata, and Y. Iwasa, Appl. Phys. Lett. 57 (1990) 1928.

14. D. H. Kim, K. E. Gray, R. T. Kampwirth, J. C. Smith, D. S. Richardson, T. J. Marks, J. H. Kang, J. Talvacchio, arid M. Eddy, Physica C 177 (1991) 431.

15. J. A. DeLuca, P. L. Karas, P. J. Bednarczyk, and J. E. Tkaczyk, MRS Fall Meeting, Boston MA (Dec. 1991)

16. J. P. Singh, H. J. Leu, R. B. Poeppel, E. Van Voorhees, G. T. Goudey, K. Winsley, and D. Shi, J. Appl. Phys. 66 (1989) 3154.

17. J. P. Singh, Argonne National Laboratory, private communication (1991).

18. I. Matsubara, H. Tanigawa, T. Ogura, H. Yamashita, M. Kinoshita, and T. Kawai, Appl. Phys. Lett. 57 (1990) 2490.

19. J. R. Hull, Cryogenics 29 (1989) 1116.

20. J. L. Wu, J. T. Dederer, P. W. Eckels, S. K. Singh, J. R. Hull, R. Poeppel, C. A. Youngdahl, J. P. Singh, M. T. Lanagan, and U. Balachandran, IEEE Trans. Magn. 27 (1991) 1861.

21. J. Wu, J. T. Dederer, S. K. Singh, and J. R. Hull, in 14th Symposium on Fusion Engineering (San Diego, 1991). 
22. B. R. Weinberger, L. Lynds, and J. R. Hull, Supercond. Sci. Technol. 3 (1990) 381388.

23. B. R. Weinberger, L. Lynds, J. R. Hull, and U. Balachandran, Appl. Phys. Lett. 59 (1991) 1132-1134.

24. J. R. Hull and I. T. Myers, in Proc. ASME Winter Annual Meeting AES-Vol. 9 (San Francisco, Dec. 1989) 49-53.

25. J. R. Hull and J. He, in Proc. Intersoc. Energy Conv. Engng. Conf. 4, (Boston, Aug. 1991) pp. 570-575. 


\section{FIGURE CAPTIONS}

Fig. 1. Intrinsic irreversibility curves for major HTS materials. (courtesy D. H. Kim and K. E. Gray, Argonne National Laboratory)

Fig. 2. Helium boiloff from an experimental HTS current lead as a function of current compared to theoretical performance from normal-metal leads. 


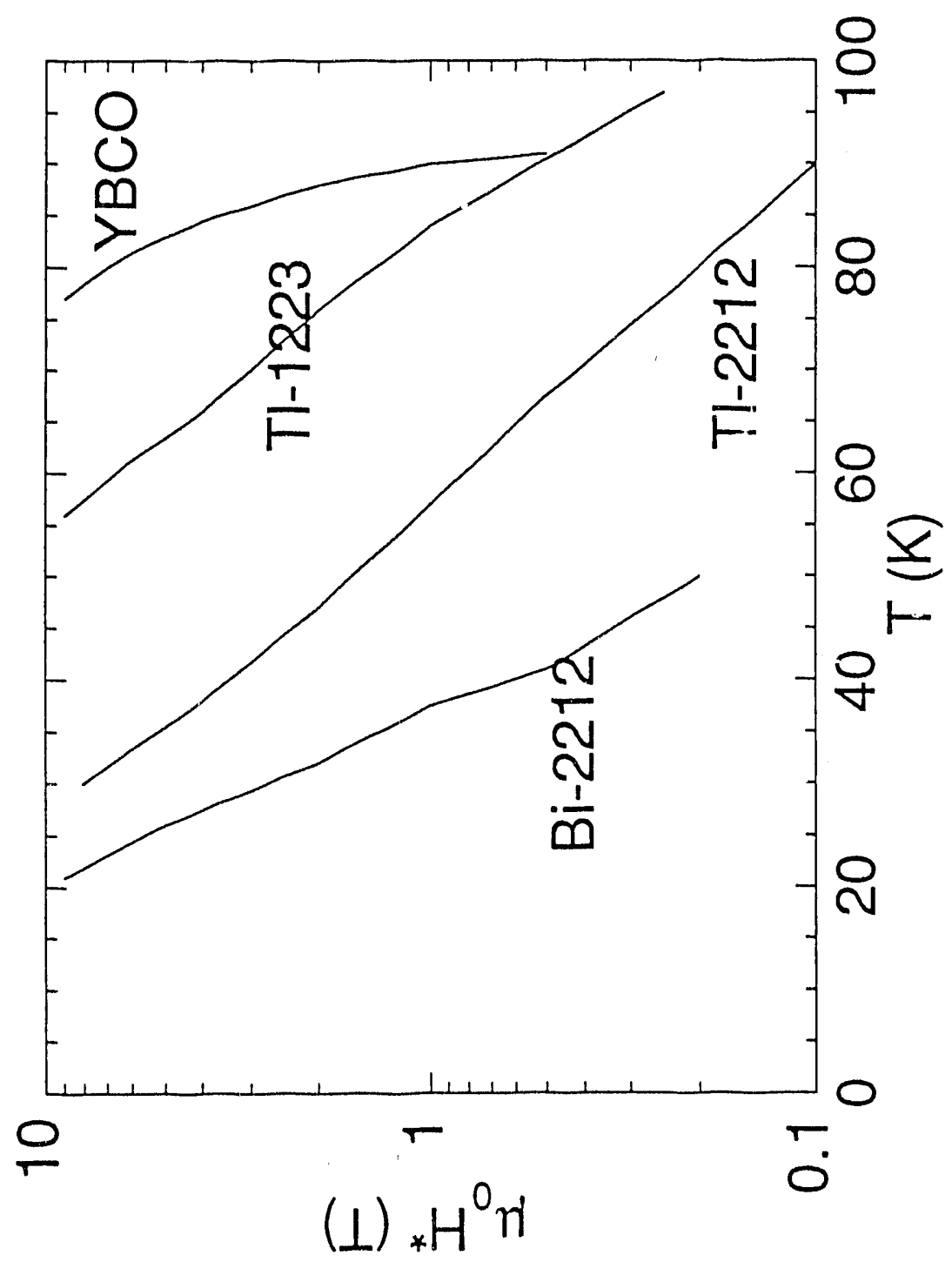

i̊ํㄴ 


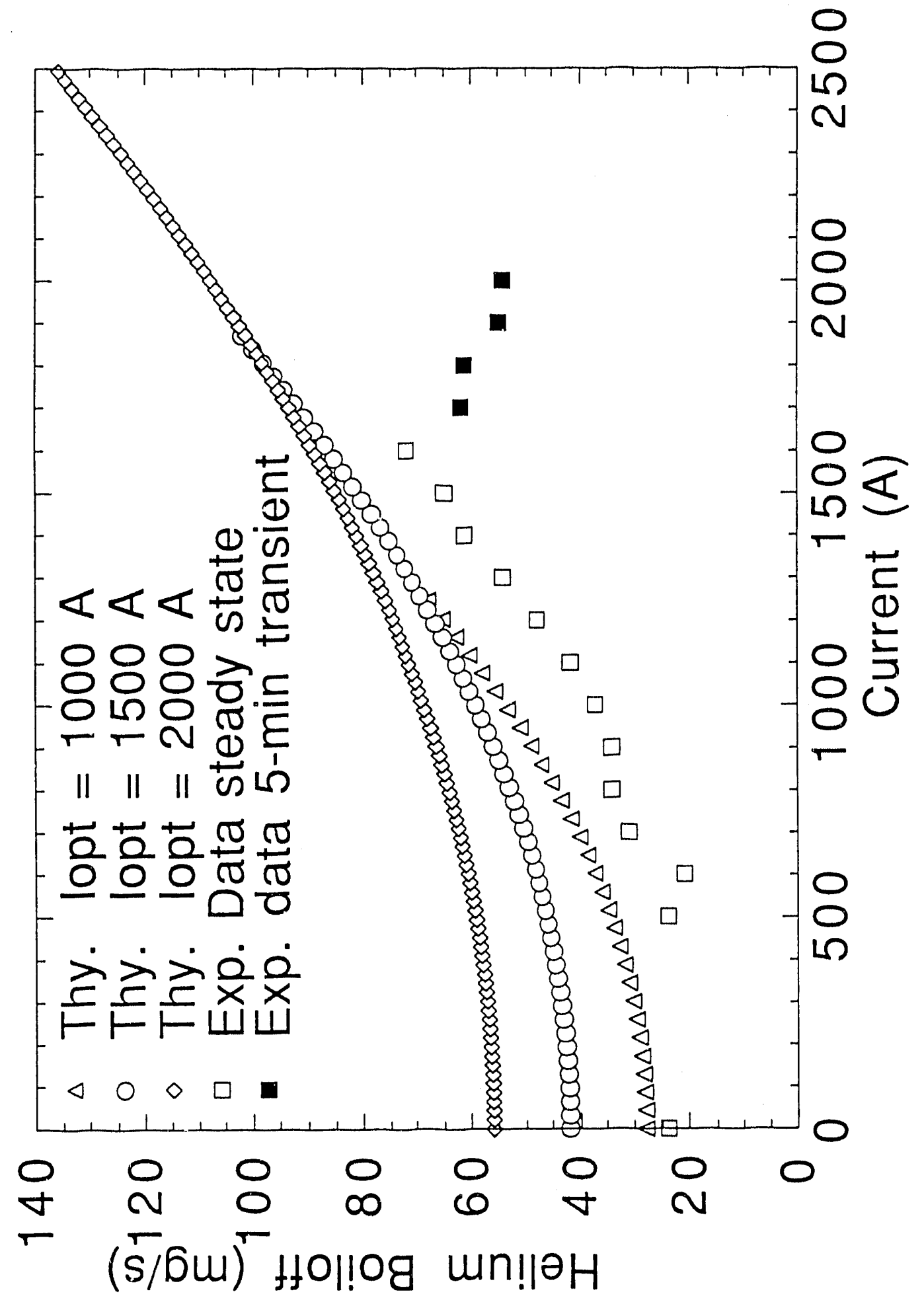

N 

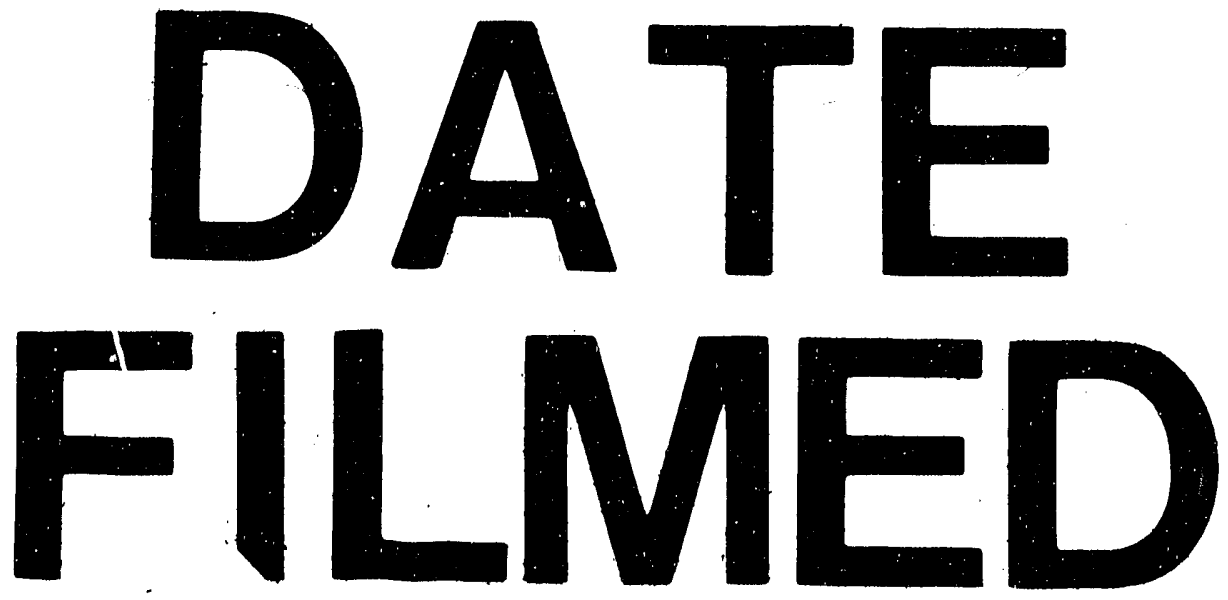

8
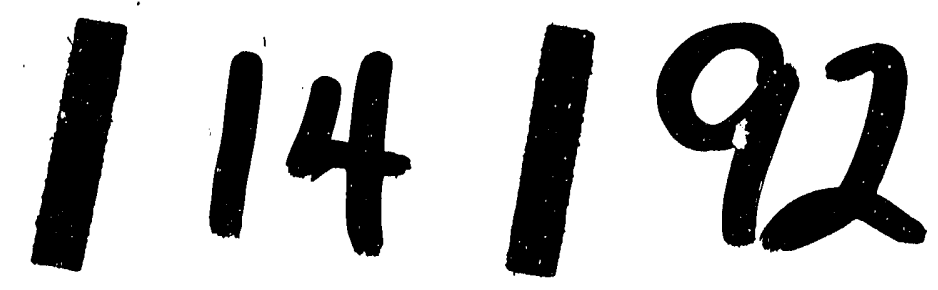
